\title{
Contributions to the adoption of a service-oriented architecture in an autarchy
}

\author{
Paul Andre da Fonseca Moreira Coelho, Rui Manuel da Silva Gomes \\ Escola Superior de Tecnologia e Gestão, Instituto Politécnico de Viana do Castelo, 4900-348, Viana do Castelo, Portugal
}

\section{Email address}

padfmc@gmail.com (P. A. d. F. Moreira Coelho), rgomes@estg.ipvc.pt (R. M. d. S. Gomes)

\section{To cite this article:}

Paul Andre da Fonseca Moreira Coelho, Rui Manuel da Silva Gomes. Contributions to the Adoption of a Service-Oriented Architecture in an Autarchy. American Journal of Software Engineering and Applications. Vol. 3, No. 4, 2014, pp. 46-55.

doi: $10.11648 /$ j.ajsea.20140304.12

\begin{abstract}
The implementation of e-Government in public administration allows the development of more service channels with its suppliers and relationships with its citizens, promoting a safe service and securing the confidentiality of information. Service-oriented architecture (SOA) is a new way of developing systems that promotes a shift from writing software to assembling and integrating services. By adopting an SOA approach and implementing it using supporting technologies, companies can build flexible systems that implement changing business processes quickly, and make extensive use of reusable components. In this paper we describe the approach we followed in adopting an SOA in an autarchy with regard to the implementation of a process of public procurement integrated with the existing systems. We present the steps followed, the difficulties and the advantages of this integration, pointing out the facilitator role of Web services in the design and implementation of the Service.
\end{abstract}

Keywords: SOA, Integration, Services, Business Processes, Public Administration

\section{Introduction}

The service-oriented architecture (SOA) approach is the latest in a long series of attempts in software engineering that try to foster the reuse of software components [1]. The SOA is a new way of developing systems that promotes a shift from writing software to assembling and integrating services [2].

As reported by [3], SOA can be viewed from three different perspectives:

- The business perspective: Set of provided services by an organization to its stakeholders;

- The architecture perspective: An architectural view which consists of a service provider, a requester, and a service discovery;

- The implementation perspective: Set of standards, tools, and technologies, such as Web services.

SOA usually refers to an organizational ICT architecture whose unifying or coherent form serves the purpose of organizing and designing the construction, selection and interconnection of hardware, software and communications assets of the enterprise. With [1], we wish to stress the fact that as an enabler of application integration, it brings an undisputable strategic value. Technically, the main components of SOA are:

- The service directory, where all information about all available services is maintained;

- The service provider, which aims to offer services by putting appropriate entries into the service directory;

- The service requester, which uses the service directory to find an appropriate service, i.e. a service that matches its requirements. Some of the most important standards are:

- SOAP (Simple Object Access Protocol) defines a mechanism for communicating with the Web services over the Internet. It deals with the format of the messages exchanged between the service requester, the service provider and the service directory.

- WSDL (Web Services Description Language) defines the structure and the contents of the service directory. Two related pieces of this standard are: 1) service types which are typically standardized by standards; and 2) actual business information.

- UDDI (Universal Description, Discovery, and Integration) provides the capability to describe a Web 
service, without the need to have it formally standardized. A WSDL description of a Web service provides all information needed to actually invoke it [4].

SOA simplifies the development of enterprise applications as modular, reusable business services that align existing information technology infrastructure and systems to achieve end-to-end enterprise integration by removing redundancies, generating collaboration tools, and streamlining information technology processes. By adopting an SOA approach and implementing it using supporting technologies, companies can build flexible systems that implement changing business processes quickly, and make extensive use of reusable components [5]. SOA supports an information environment built upon loosely coupled, reusable, standards-based services. Increased interoperability, increased business and technology domain alignment, increased return on investment, and increased organizational agility are all benefits of an SOA approach [6].

Although many organizations are considering adopting SOA, some are doing this from a purely IT perspective, while others are really looking for a new way to do business. ITs make up a part of the main budget of many businesses, especially those that offer financial services. They affect all aspects of these organizations, including the costs of daily transaction, but they give very good results in terms of efficiency. They allow interdisciplinary collaboration through the company's business, and this leads to better inter-departmental cooperation, better information sharing, and greater capacity for internal union in order to compete in the market. They improve many business processes, they increase productivity throughout the organization, and they lead to more productive and more efficient processes, whether internal or related to commercial partners and customers. An SOA is difficult to implement, manage and control, not because of the technology but due to the organizational, cultural and behavioral aspects that guarantee the SOA's success. Despite the huge progress that has been made with the standards, tools for support and development, and run-time platforms, some issues are still to be solved. These include support for transactions, delays in execution times, safety concerns, and many others.

Organizations have to establish an approach to SOA architecture in which their processes and the control of their business architecture adjusts to the requirements of the SOA. The application of an SOA in businesses depends on their level of maturity regarding the existing architecture and applications. The adoption of an SOA in a given project can be an integration or a partial or full migration, depending on the costs, relevance and life-span of the original applications [7], [8], [9], [10], [11].

The SOA is fundamental for the modernization and optimization of any business. The orientation of an SOA for a business aims to define its services with the business context always in mind. The business defines the policy for the development of new SOA projects, it establishes priorities with regard to business needs and the strategy for orienting services, either by integration or full or partial migration, which is a key factor in the evaluation of the benefits that an SOA brings to the organization [12].

The SOA is an architecture that establishes a new paradigm for information systems, one which is closer to the real business needs of a company, allowing its business processes to be independent from technology, based on the concept of service.

\section{Case Study}

In an ideal system, the ITs should be the means by which these services are supported, not factors that condition the modelling of procedures. Taking into account the advantages of SOAs and the need to speed up the processes related to the providers of public administration, here we present the following approach for the integration of a platform for public procurement with the existing systems in an autarchy, adopting an SOA.

\subsection{Research Method}

Olesen and Myers' research [13], which investigates the relationship between the introduction of groupware into an organization and the consequent changes in individuals' work habits and the structure of the organization, was supported by action-research method. The authors argued that the method "enables a researcher to intervene in the organization while at the same time generate knowledge about the process." (p. 321). They approached research in an interpretive manner, which allowed them to focus their research on how individuals attempted to make sense of the specific situation. Like Olesen and Meyers [13], we employed a five-stage action research cycle. The stages are as follows:

- Diagnosing: identifying the research question.

- Action Planning: determining the actions to be undertaken to address the research question.

- Action Taking: conducting and monitoring the planned actions.

- Evaluating: determining if the actions have addressed the research question.

- Specifying Learning: documenting the knowledge obtained by conducting the project.

\subsubsection{Diagnosing}

The challenges of a society that is intended to be modern and competitive in the global market are directly related with the degree of evolution of each public administration. Faced with the challenges generated by today's knowledge society, it becomes necessary to incorporate and to implement, in a continuous way, technological development and modernization at all levels of activity, from education to culture, also including the business activities. However, by cross- articulation with all of the agents of this society, it is in public administration that this 
modernization and technological development will be most necessary in terms of the income and efficiency, and transparency and productivity that it will bring to their services.

Considering the advantages of SOAs and the importance of adapting information systems to the real needs of a business, the aim is to carry out a study of the implementation of the architecture that is oriented towards services. The objective is to improve and optimize the procedures and services of the internal workings of an autarchy, as well as those provided to its suppliers and citizens.

PECP is a web platform that controls and manages the processes involved in public procurement through their various stages. Use of the platform is obligatory and acquired from external bodies certified by CEGER (Centre for the Management of the Information Network of the Portuguese Government), and is in accordance with the code of public procurements. The direct stakeholders of the platform are defined as the adjudicating body, in this case the autarchy, which opens to tender the public acquisition procedure (PPA) and manages the platform from the applications point of view; the suppliers, which compete in the PPA; and the jury, which evaluates the proposals submitted and gives its adjudication.

It is necessary to note that this process is not integrated with the autarchy's existing information system as our aim is to adopt an SOA, setting out a new approach and identifying its advantages for the autarchy.

\subsubsection{Action Planning}

After identifying the objective of the project, the next step was to plan a study and survey of the workings of the autarchy, according to the concept of value chain, proposed by Michael Porter [14], [15].

The process and procedure of public contracts was analyzed, as well as the respective support platform and its sectional and functional interdependencies. An analysis of the existing information system was also planned applications, data bases and support technologies. The approach to the development of the SOA was selected, with the proposal made by Erl [16] being chosen. This begins with a Top-Down approach, followed by a Bottom-Up approach. The tools needed for the integration of the process of public procurement were identified, mainly with regard to the creation of diagrams that represent the architecture of the information systems and ontology of the organization, IDE[1] of programming, Business Process Modelling [2] with a BPEL[3] extension to describe the interaction between the different applications, and to allow the generation of WSDL and XML to create the web services.

The chosen tools were: Dia [17]; Protégé [18]; Intalio [19] and JDeveloper [20]. The Dia application is an open

\footnotetext{
${ }^{1}$ Integrated Development Environment

${ }^{2}$ BPM

${ }^{3}$ Business Process Execution Language
}

source tool which allows the creation of diagrams, flowcharts and organigrams Protégé is an open source platform for editing the ontology of organizations and knowledge data bases. For the representation of the processes, Intalio Designer, an open source framework for BPMN modelling was used. Jdeveloper was selected for the development of the web services, being an IDE in Java of Oracle. This allows the web services to be represented in BPEL through the creation of a project of the JAVA Web Service type. These will be generated later and installed in the application server of the Oracle architecture. The applicational server is managed by the Oracle Enterprise Manager $10 \mathrm{~g}$.

\subsubsection{Taking}

The next stage was to develop the applicational integration following the Top-Down and Bottom-Up approach.

\subsubsection{Top-Down Analysis}

The development stages were as follows:

1st. Define the most relevant elements of the ontology of the Autarchy

In this stage, the ontology of the institution was surveyed in the Protégé framework. The most relevant elements of the organization were considered to be human resources management; management in terms of education, bodies, technologies and information systems (TSI); and management of documents, services and infrastructures. The element 'bodies' includes the executive board, collaborators, citizens and suppliers. The TSI are a key element for the evolution of an organization as they are made up of the active and passive infrastructures, and the Information System software. Documentation management is relevant because all the information regarding processes in the organization is managed through this element.

Services are a major part of the ontological elements since, by definition, they are the organization's reason for existing. This element covers the movements that can be fiscal or counter-orders; work related to infrastructures; complaints; citizens' web area; financial area composed of treasury, accounts and provision elements; cultural promotion; communication service; requests related to sanitation and water supply, library services, availability of cultural and sport venues, licensing, museum, renting, weather services, archive services and transport services. The provisioning element covers the elaboration of the public procurement process which is divided into purchases and payments. The final element is infrastructures, which can be cultural or sport related.

$2 n d$. Align the most relevant business models, according to the analysis made in the first point

In the analysis of the most relevant business models, taking into account the services to be offered to the citizens and the procedures that are important for the institution to function, following the ontology of the institution, the following business processes were identified: licensing request; reception; service request; public procurements; 
meeting payment; complaints; information.

Licensing requests are defined as the process of requesting the approval and issue of licenses in different areas, such as private building work, business establishments, and advertising, among others. The process of reception consists of procedures for the payment to the institution of services, taxes, licenses, sales or fines on the part of citizens. Service requests are the process of citizens' acquisition of a service from the autarchy. Public procurements are the acquisition of goods and services following the public procurement rules. This is analyzed in detail as it was chosen for the development of an SOA, integrating the PECP platform with the existing systems. Meetings payments make up the process of paying amounts to politicians for their attendance at meetings. Complaints is a process that is covered by law and all citizens can make a complaint if they are not satisfied with the autarchy's services. The information procedure can be a request for or a submission of Information in order to establish communication between the institution and the citizen about any issue.

\section{$3 r d$. Carrying out an analysis regarding services}

Based on the processes identified and carrying out an analysis regarding services, bearing in mind the simplification and speeding-up of the processes and business model, the following services were obtained: licensing; treasury; public procurements; service requests; and communication. In the next stage, only the public procurement system is analyzed, following the proposal for this project.

4th. Proceeding to the design regarding services

For the design of the SOA in the top down approach, the process of public procurement was described, presenting all the tasks from the initial acquisition request to the payment for the acquisition of services or goods. For each task, the description, actions carried out, and departments involved were all defined.

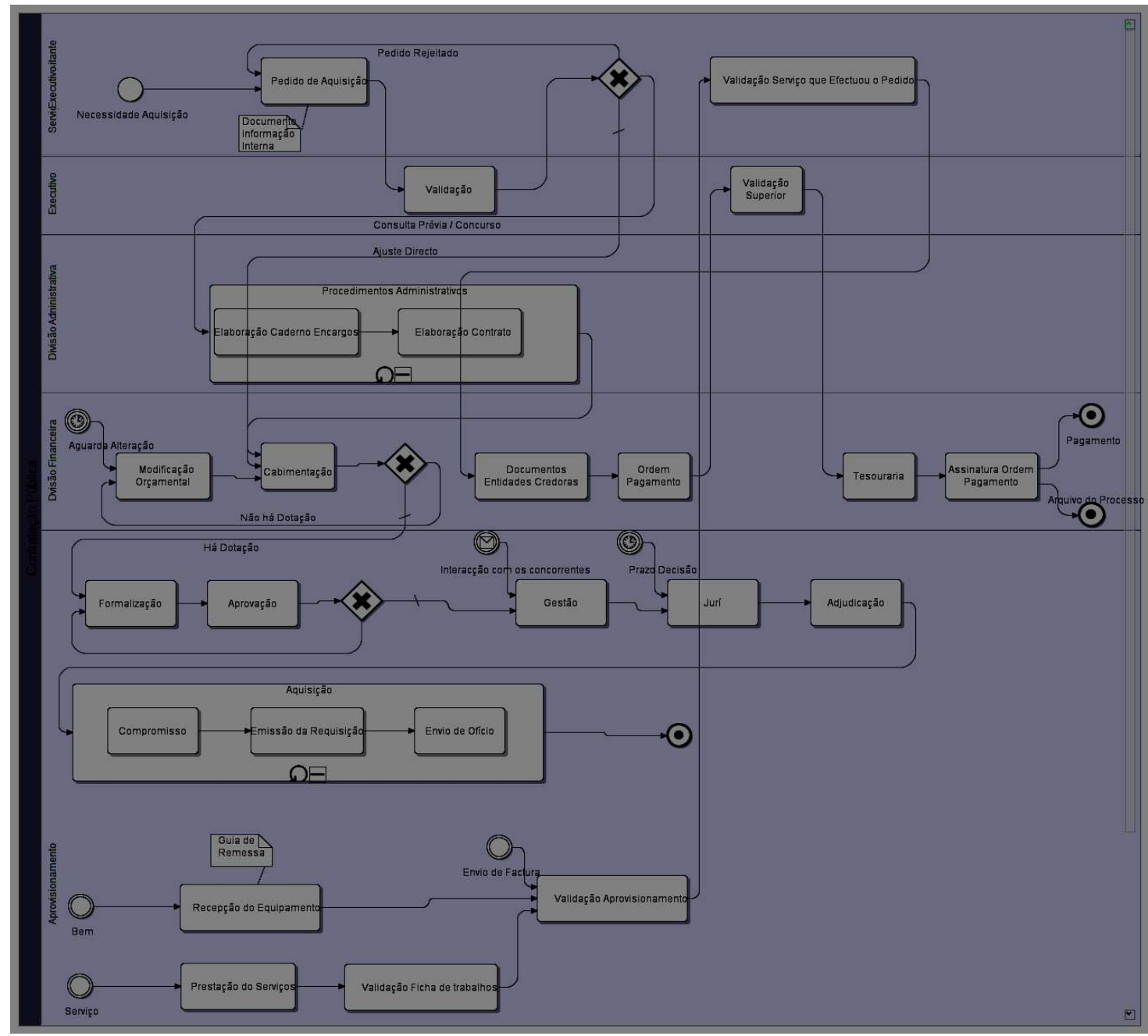

Figure 1. PECP Modelling.

\section{$1^{\text {st }}$ Task-Acquisition Request}

Description - The acquisition request is made according to the needs of the department and whether it is a direct adjustment, previous consultation, or tender.
Actions - Drawing up of the type of request; appending the technical characteristics.

Department - Any

2nd Task - Validation 
Description - The acquisition request is authorized or not.

Actions- Dispatch about the request

Department - Mayor's Office

3rd Task - Administrative Procedures

Description - All the necessary documentation is drawn up for the type of procedure.

Actions - Preparation of the administrative documentation

Department - Administrative

4rd Task - Financial Procedures

Description - The request is validated financially according to the budget and rubric corresponding to the official accounts plan (POCAL).

Actions - The appropriate part for the expenditure is selected.

Department - Financial

$5^{\text {th }}$ Task - Formalization

Description - Opening of the PPA (Public Acquisition Procedure)

Actions- A new process is opened; all the documents pertaining to the process are introduced (book of charges)

Department-Supplies

6th Task - Approval

Description - Validates the PPA data

Actions - The approver checks that the PPA is correct; validates the PPA to make it available to the market

Department - Appointments

7th Task - Management

Description - Charged with putting the PPA on the market.

Actions - Communication between candidates and the institution, dealing with doubts and possible changes.

Department - Appointments

8th Task - Jury

Description - Decision about the proposals

Actions - Validate the proposals; Analyze the proposals for the PPA according to the rules of the tender; Chose the winning proposal

Department - Appointments

9th Task - Adjudication

Description - Responsible for registering the intention of adjudication of the system.

Actions - Final validation of the Jury's decision

Department - Executive Board

10thTask - Acquisition

Description - the goods or service are received

Actions - The data related to the management of stocks and register/patrimony are updated; the acquisition is validated by the requesting supplies section

Department - Supplies/Requester

11th Task - Payment

Description - Payment of the acquisition.

Actions - Verification of the documents of the creditor bodies; Elaboration of the payment order; Payment.

Department - Financial and Executive Board

An initial modelling process of the public procurement process was developed using the application Intalio Designer, Figure 1.

The diagram shows the tasks and respective work flowcharts. The public procurement process is defined as the main pool and the sub-processes are defined as lanes of the departments involved, these being: requesting sector; executive board; administrative division; financial division; supplies.

\subsubsection{Bottom-Up Analysis}

The stages developed were:

1st. Definition of the model for service applications

Give that the information system of the institution possesses different applications and data bases with different architectures, an analysis is made of the interactions between the different technologies in which it makes sense to adopt the bottom up approach. The diagram in Figure 2 shows the various existing architectures and their interconnections.

Regarding the public procurement process this is under study, it became clear that it depends on the document management system - GSP/GSE, of the ERP and on the public procurement platform (PECP) that can be found online. These systems have different architectures that require integration, thus necessitating the creation of web services.

$2^{\text {nd }}$. Proceed to the design of the applications of services defined in the model

In the bottom up approach, the public procurement process encompasses more tasks then the top down approach. This is due to the fact that establishing the integration requires the introduction of stages of interconnection with the different systems. The new tasks were: putting the request in the document management system; putting the request in the ERP; putting in the PECP; updating the acquisition in the ERP; registering the acquisition in the ERP.

1st Task - Putting the request in the document management system

Description - Send through the document management system

Actions- Putting the request in the document management system; appending technical documentation

Department - Any

2nd Task - Putting the request in the ERP

Description - The request is introduced in the financial management application

Actions - Putting in the ERP

Department - Financial

3rd Task - Putting in the PECP

Description - The request is introduced in the PECP

Actions - Putting the process in the PECP

Department - Supplies

4th Task - Updating the acquisition in the ERP

Description - The request is introduced in the ERP

Actions - The ERP is updated with the winning proposal; the winning body is attributed to the tender in the ERP. 


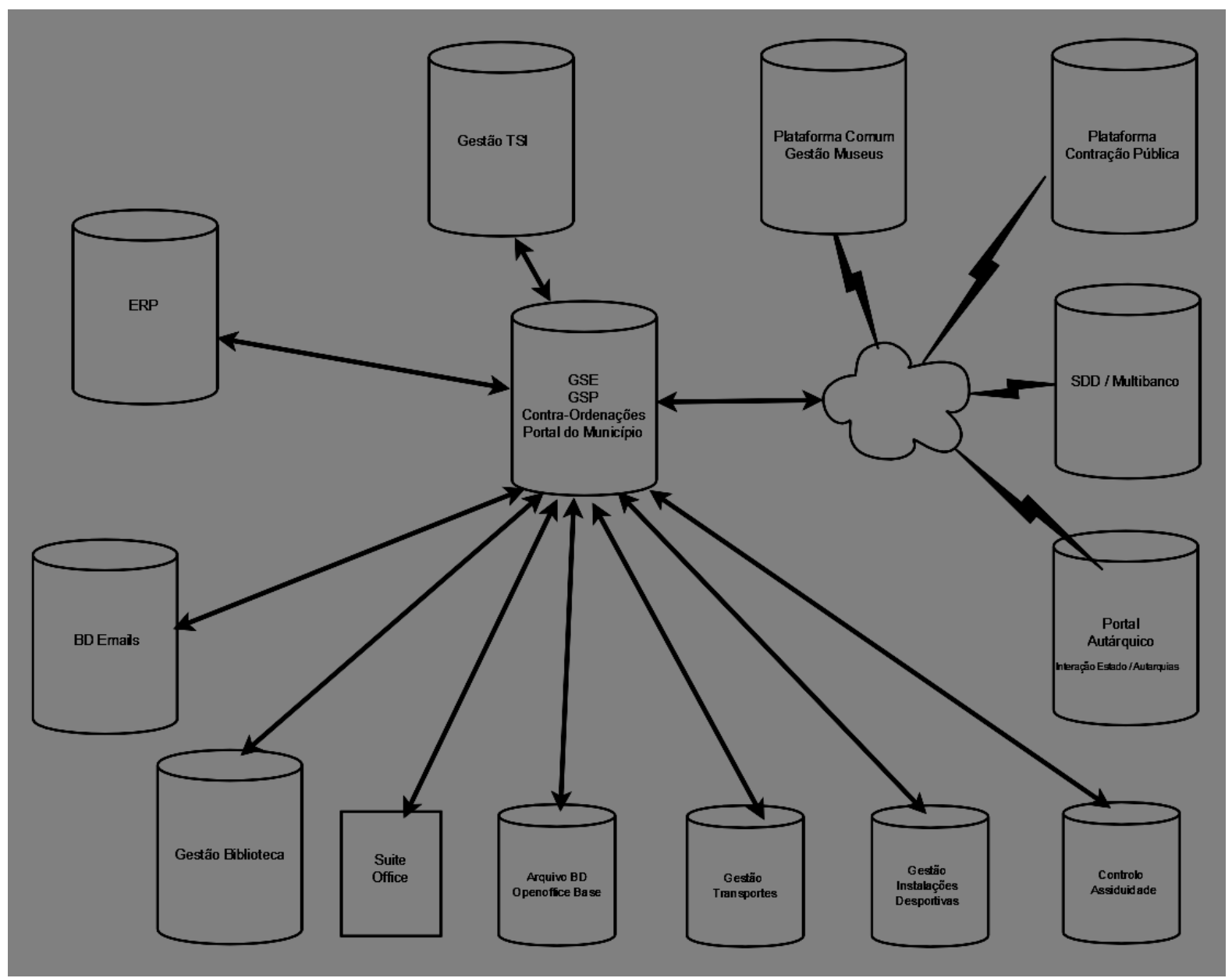

Figure 2. Bottom Up Analysis.

Department - Supplies

5th Task - Registering the acquisition in the ERP

Description - Registering the acquisition in the ERP. The data relating to the management of stocks and register/patrimony are updated.

Actions - Registering in the ERP management of stocks module; Registering in the ERP register/patrimony module.

Department - Supplies

The modelling in the Intalio Designer shows the introduction of new tasks in the BPMN diagram with regard to the respective lanes of the stakeholder departments, Figure 3.

The diagram becomes more complex but it is the only way to take advantage of the existing systems, establishing the interconnection and the orientation to the business model based on the SOA.

\subsubsection{Implementation}

The final phase is the implementation, where the project's web services were developed. The development of the services is carried out based on the new tasks found in the modelling for the integration of the different existing architectures. The need arises to create the following web services: GspGseWS; ErpWS; PecpWS.
The GspWS web service includes methods which allow the integration with the document and process management system (GSP/GSE), the ErpWS web service includes methods which allow the integration with the ERP system, and the PecpWS web service has methods for the PECP.

The IDE JDeveloper allows the diagram and generation of the BPEL code for the creation of the web services.

a) Web service GspGseWS

The GspGseWS web service is composed of the following methods:

- $\quad$ public Vector GspGse_ws(),

- public Vector GspGse_ConfereFatura_ws(Vector res_ParaConferencia).

The GspGse_ws method makes the request in the document management system (GSP/GSE) for the acquisition resulting in a vector composed of the requisition sector, the internal information number, the products required, the units, the values, the justification for the acquisition, date of the request and a Boolean according to whether the acquisition is approved or not.

The GspGse_ConfereFatura_ws method verifies the invoice taking as parameter a vector with the sector of the acquisition request, the external information number, the winning supplier, the products to be supplied, the units and 
the values. A vector is returned with the sector of the acquisition request, internal information number, the observations about the verification of the invoice and the Boolean result of the confirmation.

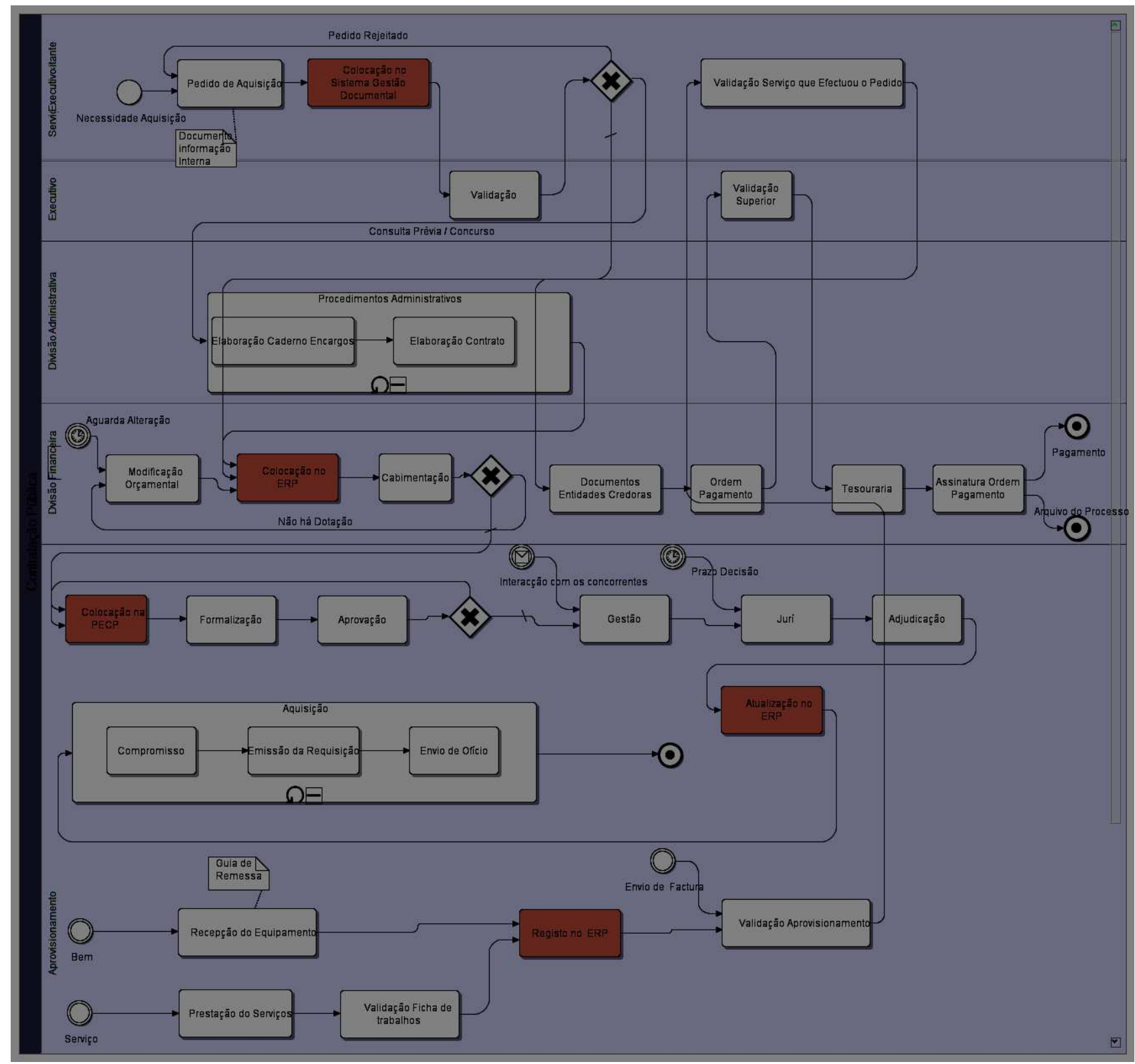

Figure 3. Bottom Up Modelling PEC.

What follows is part of the GspGseWS web service code. ....

$<$ element name="GspGse_ConfereFatura_wsElement" $>$ $<$ complexType $>$

$<$ sequence $>$

$<$ element name="n_inf_int" type="int"/> $<$ element name="resultadoPecp"

type="ns1:vector" nillable="true"/>

$<$ element name $=$ "res" type="boolean"/> $</$ sequence $>$

$<$ complexType $>$

$</$ element $>$

$<$ element

name="GspGse_ConfereFatura_wsResponseElement">
$<$ complexType $>$

$<$ sequence $>$

$<$ element name="result" type="ns1:vector" nillable="true" $/>$

$</$ sequence $>$

$</$ complexType $>$

$</$ element $>$

$<$ element name="GspGse_wsElement" $>$

$<$ complexType $>$

$<$ sequence $>$

$<$ element name="setor" type="string"

nillable $=$ "true" $/>$

$<$ element name $=" n \_$inf_int" type $=$"int" $/>$

$<$ element name $=$ "produtos" type $=$ "string"

nillable $="$ true" $/>$ 


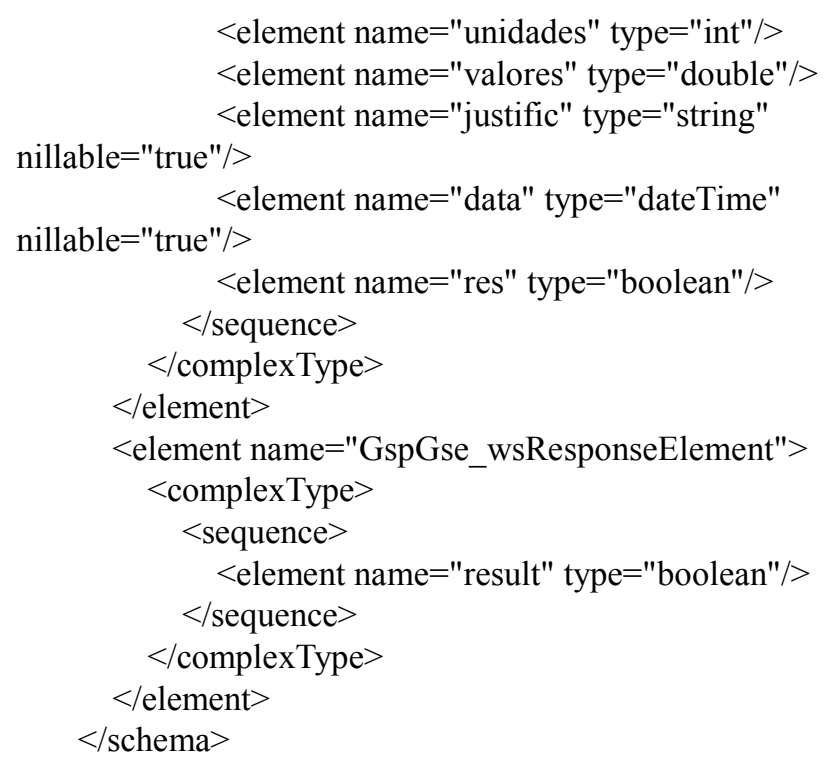

b) ErpWS Web service

The ErpWS web service is made up of the following methods:

- $\quad$ public Vector Erp_ws(Vector res_erp)

- public Vector Erp_ParaConferencia_ws( Vector resPecp)

- public void Erp_RecebeConferencia_ws(Vector res Conferencia)

The Erp_ws method makes the register of the acquisition in the ERP, taking as a parameter a vector composed by the requisition sector, the internal information number, the products required, the units, the values, the justification for the acquisition, date of the request and a Boolean according to whether the acquisition is approved or not. It returns as a result a vector with the external information number, the products required, the units and the values.

The Erp_ParaConferencia_ws method receives the information on the adjudication taking as parameters the external information number, the invoice number, the winning supplier, the products to be supplied, the units and the values. It returns a vector with a Boolean that indicates that it was already received for verification, the sector of the acquisition request, and the internal information number.

The Erp RecebeConferencia ws method receives as a parameter a vector with the sector of the acquisition request, the internal information number, the observations about the verification of the invoice and the Boolean result of the confirmation.

c) PecpWS Web service

The PecpWS web service is made up of the following methods:

- $\quad$ public void Pecp_ws(Vector Res_erp)

- $\quad$ public Vector PecpResult_ws()

The Pecp ws method carries out the collocation of the acquisition request in the PECP taking as a parameter a vector composed of the external information number, the products required, the units and the values.
The PecpResult_ws method results in a vector composed of the external information number, the invoice number, the winning supplier, the products to be supplied, the units and the values.

d) BPEL Description of the Process

The public procurement process, in the modelling in BPEL, based on a bottom up approach from the web services, can be described in the following way:

1. The request is made in the GSP which makes the GspGse_ws web service available with the content of the acquisition request;

2. With the result of the web service of point 1 , the Erp_ws web service is performed to introduce the acquisition request in the ERP;

3. After validation by the financial area, the result of the information of point 2 is introduced as a parameter in the PECP from the Pecp_ws web service ;

4. From the PecpResult_ws web service, the result of the adjudication of the acquisition of the public procurement platform is made available;

5. After reception of the invoice, the data of the adjudication are put in the Erp_ParaConferencia_ws as parameters. The function returns the document and the results of the adjudication.

6. From the GspGse_ConfereFatura_ws web service it is sent for verification for the GSP/GSE application based on the parameters of the requesting sector and the result of the information of point 5 , which in turn returns the result of the validation;

7. Finally the ERP receives the result of the verification from the RecebeConferencia_ws web service in order to proceed to payment of the invoice.

\subsubsection{Evaluation}

The aim of this project was to contribute to the adoption of an SOA in an autarchy. However, although this is only one step in this process, it seems to us that the use of both top down and bottom up approaches made it possible to analyse the advantages and disadvantages in the decisionmaking process, having carried out the actions that satisfied the aim.

With the implementation of the adoption of the SOA, in the majority of cases, it is possible to take advantage of the existing applications based on the integration of standard technological mechanisms, thus reducing costs with the evolution in this kind of architecture. The evolution to the SOA allows the dependency of the architecture of the technological layer to be reduced so that it favours the services of the institution's business model. The progressive transition to the SOA also leads to the optimization of human resources and an improvement in the functioning of the processes in the organization, resulting in greater efficiency and speed in the responses to citizens' requests and needs.

The integration of the public procurement system based on an SOA seems to be the solution, as it has the following advantages: 
- $\quad$ greater speed in the public procurement processes;

- it avoids the reintroduction of the information in the various systems of applications;

- $\quad$ simplification of the public procurement process;

- greater financial control of the public procurement process;

- more efficient control of the duration of the tenders and their better management;

- dematerialization of the processes. Elimination of paper documentation, allowing the connection between the various systems of applications ;

- $\quad$ speed in the preparation of payments for the acquisition of goods and services;

- $\quad$ future SOA projects, adaptability in incorporating necessary changes and integrations.

\subsubsection{Specifying Learning}

With the development of this project, we realized the importance of the initial study of the ontology, workings and culture of the organization as it allows detailed knowledge to be acquired, as well as its particular features. It is important to assimilate the existing processes in the organization and identify the interactions that take place with their actors. This kind of survey must be carried out and supported in communication with the different elements of the departments and their functional units. The creation of work teams across the projects facilitates and speeds up the resolution of problems. It is only possible to find a correct and true approach in the organization in this active and participative way, as it becomes crucial in the elaboration of IT projects.

Projects must also begin on a small scale, and then the SOA model can be applied gradually. This form of implementation makes sense given the quantity and complexity the processes and the different application that already exist in organizations. All activity in an organization is defined in processes that establish patterns of response and routine that are appropriately structured and optimized.

In information systems, the applications that are inherited and the various architectures should be analyzed to decide whether there is to be integration or substitution in the new projects. The evaluation needs to be done bearing in mind the question of finances and the impact with regard to the needs of the business. This change should have as little impact as possible but it must always depend on the speed of change in the market.

The implementation of an SOA requires constant supervision, in that it is dynamic and is constantly iteration; for this reason, the governance of the SOA must be an ongoing concern for organizations.

\section{Conclusion}

In this paper we described an approach followed in the adoption of an SOA in an autarchy with regard to the implementation of the integration of the public procurement process (PECP) with the existing information system in the organization. We presented the activities developed in the diagnosis, action planning, action taking, evaluation, and specifying learning phases.

We reached the conclusion that the adoption of an SOA in an organization must always be oriented by the business itself, even though it is technological; that the methodology has to begin with a Top-Down approach, followed by a Bottom-Up approach, given that the organization has a high number of systems. We also noted that the results achieved were as advantageous with regard to the functioning of the public procurement process, integrated with the existing IS, as in the future development of the SOA in the autarchy.

\section{References}

[1] F. Leymann, D. Roller, and M. T.Schmidt, "Web services and business process management," IBM Systems Journal, Vol.41, No.2, 2002.

[2] Z. Mahmood,"Service Oriented Architecture: Potential Benefits and Challenges," Proceedings of the 11th WSEAS International Conference on COMPUTERS, Agios Nikolaos, Crete Island, Greece, July 26-28, 2007.

[3] M. Ibrahim, and G. Long, "Service Oriented Architecture and Enterprise Architecture" IBM developer Works, IBM Corporation, May 2007.

[4] B. Baskerville, M. Cavallari, K. Hjort-Madsen, J. Pries-Heje, M. Sorrentino, and F. Virili, "Extensible Architectures: The Strategic Value of Service Oriented Architecture in Banking," proceeding of European Conference on Information Systems (ECIS), 2005.

[5] IBM, "The Solution Designer's Guide to IBM on Demand Business Solutions," IBM 2005.

[6] N. Bieberstein, S. Bose, M. Fiammante, K. Jones, and R. Shah, Service Oriented Architecture (SOA) Compass Business Value, Planning, and Enterprise Roadmap: IBM Press, published by Pearson plc, 2006.

[7] Chen, F. et al., 2005. Feature analysis for service-oriented reengineering. Software Engineering Conference, 2005.APSEC'05. 12th Asia-Pacific, 15-17, 8 p.

[8] Chung, Davalos, 2007. Service-Oriented Software Reengineering: SoSR. 40th Annual Hawaii International Conference on System Sciences (HICSS'07). p. 172c.

[9] Kontogiannis, K., Lewis, G. and Smith, D., "The Landscape of Service-Oriented systems: A Research Perspective for Maintenance and Reengineering", Site: http://www.cs.vu.nl/csmr2007/workshops/1$\% 20$ PositonPaper-SOAM-v2-4.pdf.

[10] Zhang, Z., Lui, R., Yang, H., Service Identification and packaging in service-oriented reengineering. In: Proceedings of Seventeenth International Conference on Software.

[11] Umar, A., Zordan, A., 2008. Reengineering for Service Oriented Architectures: A Strategic Decision Model for Integration Versus Migration. DICS. Fordham University. 
[12] Bell, M., 2008. Service-Oriented Modeling - Service Analysis, Design, and Architecture. New Jersey. Wiley.

[13] K. Olesen and M.D. Myers, Trying to improve communication and collaboration with information technology: An action research project which failed. Information Technology and People, 12(4),1999, pp. 317328.

[14] Michael Porter, Competitive Advantage, Free Press, New York, 1985.
[15] Michael Porter, Strategy and the Internet, Harvard Business Review, March 2001.

[16] Erl, T., 2008. SOA Principles of Service Design. Boston. Prentice Hall.

[17] Dia, <http://projects.gnome.org/dia/>.

[18] Protégé, <http://protege.stanford.edu/>.

[19] Intalio, BPM $<$ http://www.intalio.com/bpms/designer

[20] JDeveloper, Java SOA <http://www.oracle.com>. 